удК 340.5

И. В. Левченко

Байкальский государственный университет, г. Иркутск, Российская Федерация

\title{
РОЛЬ СРАВНИТЕЛЬНО-ПРАВОВЫХ ИССЛЕДОВАНИЙ В ОПРЕДЕЛЕНИИ ВЕКТОРА РАЗВИТИЯ ГОСУДАРСТВА
}

\begin{abstract}
АНнотАЦия. В статье обосновывается значение сравнительных исследований правовых систем в выборе заимствований или не заимствований для преобразований в государстве с учетом мировых тенденций правового развития стран. Автор обращает внимание на особенности методологии и методики проведения сравнительно-правовых исследований. Рассматриваются некоторые условия позитивного восприятия зарубежного правового опыта, адаптации правовых институтов к реалиям государственной жизни.
\end{abstract}

КЛЮЧЕВЫЕ СЛОВА. Сравнительно-правовые исследования; национальная правовая система; правовой институт; системный анализ; правовое заимствование.

ИНФОРМАЦИЯ О СТАТЬЕ. Дата поступления 1 марта 2017 г.; дата принятия к печати 10 марта 2017 г.; дата онлайн-размещения 31 марта 2017 г.

I. V. Levchenko Baikal State University, Irkutsk, Russian Federation

\section{ROLE OF COMPARATIVE LEGAL STUDIES IN DETERMINING VECTOR OF STATE DEVELOPMENT}

\begin{abstract}
The article substantiates the importance of comparative studies of legal systems in selecting borrowings or not borrowings for transformations in the state in terms of the world trends of the countries' legal development. The author draws attention to the features of methodology and methods of making comparative legal investigations. The article considers some conditions of positive perception of foreign legal experience, adaptation of legal institutions to realities of public life.

KEYWORDS. Comparative legal investigations; national legal system; legal institution; system analysis; legal borrowing.

ARTICLE INFO. Received March 1, 2017; accepted March 10, 2017; available online March 31, 2017.
\end{abstract}

Сравнительно-правовые исследования, важность и значение которых с каждым годом возрастает, являются одним из важнейших направлений научной деятельности современного государства. Сравнительно-правовые исследования представляют собой незаменимый инструмент для совершенствования национального права. Целью сравнительно-правовых исследований является изучение многообразия конкретных позитивно-правовых решений различных юридических проблем, предлагаемых национальными правопорядками в рамках единых принципиальных подходов. В эпоху когда, с одной стороны, в условиях глобализации растет взаимозависимость народов мира, а с другой стороны, проявляется стремление к национальной идентичности, сравнительно-правовой анализ получил второе дыхание. Известный французский ученый, профессор Раймон Леже отмечает, что «изучение других правовых систем позволит человеку, знакомому только с правом своей страны, открыть двери в правовую вселенную» $[1$, с. 2].

Такая категория как правовая система дает возможность оценивать и анализировать правовую реальность в целостном виде, а не отдельные ее компо-

(C) И. В. Левченко, 2017

\section{Baikal Research Journal}

электронный научный журнал Байкальского государственного университета 
ненты, что дает возможность достигать более высоких уровней обобщения, абстракции. Помимо права как стержневого элемента правовая система включает в себя множество других составляющих: правотворчество, правосудие, юридическую практику, правовую культуру, нормативные, правоприменительные и правотолкующие акты, правоотношения, субъективные права и обязанности, правовые учреждения, законность, ответственность, механизмы правового регулирования, правосознание и др. Все это отражает сложный правовой уклад определенного государства. Для определения исторической перспективы развития общества и государства, по мнению М. Н. Марченко, требуется не только и не столько изучение внутренней структуры (системы) права, сколько выяснение закономерного места данной правовой системы на основе анализа общего и особенного в социальных, политических, структурных, специально-юридических характеристиках национального права [2, с. 84]. Следовательно, важнейшим фактором в развитии права, любой национальной правовой системы, является ее взаимодействие, взаимовлияние, восприятие институтов, норм, принципов других правовых систем.

Современная российская правовая наука меняется коренным образом. Вместо теоретического всеединства, единообразия, на смену монополии на истину пришел плюрализм учений о праве и государстве. Любое из этих учений имеет право на существование, если посредством критики не доказана его несостоятельность. Большую роль при исследованиях играет методология. В. Е. Чиркин обращает внимание на то, что «ученые независимо от того, осознают это они или нет, используют такую методологию, которая определяется их мировоззрением, характером образования, практическим опытом, иногда определенным положением». По его мнению, можно выделить три главных направления в методологических подходах. Во-первых, либерально-социальное направление, которое при всем различии научных школ исходит из традиционных общечеловеческих ценностей (свобода, равенство, демократия, права человека и т. д.), из тезисов власти народа, соединяемых с идеями социального государства социальной функцией частной собственности, социальных партнерств и др. Во-вторых, социально-радикальное направление, которое представлено несколькими подходами: марксистско-ленинской концепцией права и концепциями революционеров-демократов. В-третьих, теологическое (теократическое) направление, которое очень неоднородно и является сегодня доминирующим в странах мусульманского фундаментализма [3, с. 19-21].

Вопросы методологического характера, которые касаются сравнительно-правовых исследований, нашли достаточно широкое отражение в научных трудах дореволюционных, советских и современных российских и зарубежных ученых Б. А. Грушина [4], М. М. Ковалевского [5], К. Цвайгерта [6], К. Осакве [7], В. С. Нерсесянца [8] и др. Хотя в настоящее время нет единства во взглядах на методологию сравнительно-правового исследования, основные правила, требования компаративистского анализа в основном выработаны. Проблема разработки методики сравнительно-правового анализа еще требует решения и сегодня как никогда актуальна. Отсутствие четко регламентированных методики и техники сравнительно-правового исследования может привести к серьезным ошибкам в процессе научной работы. Это в свою очередь скажется на ее результатах-выводах.

Методика сравнительно-правовых исследований часто определяется как совокупность взаимосвязанных этапов (стадий) и правил, наиболее подходящих для применения сравнительно-правового и других научных методов. Целью является выделение подобных и отличительных признаков, группировка и классификация исследуемого правового материала. Сравнение может и должно стать

\section{Baikal Research Journal}

электронный научный журнал Байкальского государственного университета 
научным и результативным, если за основу берутся не случайные факты, а типичные и достоверные факты. Важнейшим условием проведения эффективности научного анализа является однородность, однопорядковость, единосистемность сравниваемых объектов. Сравнение права представляет собой многоступенчатый процесс, поэтому требуется в любом научном исследовании четкая постановка проблемы и ее ограничений, целесообразности работы, выбор объектов для проведения сравнения. К. Цвайгерт и Х. Кетц указывают на то, что при выборе объектов сравнения должен действовать общий принцип их разумного ограничения [6, с. 63]. К. Осакве считает, что грамотный сравнительный анализ правовых систем состоит из восьми последовательных и поэтапных стадий:

1. Выявление существующих правил или подходов в системах «А» и «Б» .

2. Сопоставление установленных правил с целью познания их общих и (или) отличительных свойств.

3. Определение исторических причин существования данного правила в каждой системе.

4. Выяснение жизнеспособности, эффективности данного правила в государственном законодательстве.

5. Установление необходимости (целесообразности) внесения изменений в существующие правила или восполнение пробелов в законе системы «А» путем заимствования определенных идей из системы «Б».

6. Изучение совместимости идей, заимствованных из системы «Б», с природой права из системы «А».

7. Адаптация заимствованного правила национальным условиям правовой системы «А».

8. Решение завершающего кардинального вопроса законодательной политики, то есть вопрос о том, созрело, с точки зрения своего правосознания и правовой культуры, общество, принимающей правовой системы для принятия пересаживаемого института [7].

Специалисты также обращают внимание на то, что право любой страны невозможно понять без знания ее языка. Важное значение во время сравнительно-правовых исследований имеет учет правовых традиций, уровень юридической техники, особенности системы понятийного категориального аппарата и т. д.

Системный характер научных сравнительно-правовых исследований определяется потребностями разработки взвешенной правовой политики. Известно, что правовая политика представляет собой обоснованную, последовательную и системную деятельность государственных и негосударственных структур по созданию эффективного механизма правового регулирования [9, с. 26]. В то же время, по мнению Г. И. Муромцева отсутствие завершенной концепции нового российского общества и соответствующей правовой доктрины привело к включению в нее таких новых правовых категорий и концепций, которые вошли в нее не системно и заимствовались из плохо совмещенных источников. В большинстве случаев они заимствовались из доктрины и законодательства развитых стран, а также из международных актов [10, с. 5-6]. Данное обстоятельство приводит к негативным последствиям для российского права.

Сравнительно-правовые исследования дают возможность установить, каким образом решается одна и та же правовая проблема на международном уровне и в разных странах. Это позволяет учитывать как позитивный опыт, который может быть позаимствован, так и негативный, который следует иметь в виду и не допускать в своей юридической практике. Ю. А. Тихомиров, анализируя итоги работы XVII конгресса компаративистов (Нидерланды, июль 2006 г.), отмечал, что «по-прежнему сохраняется устойчивая тенденция рассмотрения юри-

\section{Baikal Research Journal}


дических институтов стран на широкой сравнительно-правовой основе... Заметно акцентируется внимание на некоей унифицированности институтов и норм, в меньшей степени - на национально-правовых особенностях... наблюдается повышенное внимание к проблематике соотношения и влияния международного и национального права при явном гегемонизме глобальных норм...» [11, с. 151].

В российской правовой доктрине сравнительно-правовым исследованиям всегда отводилась особая роль. Начиная с Петра I, происходило заимствование иностранных типов учреждений и регламентов. В современных условиях особенно заметным, и плодотворным, применение компаративистского подхода проявляется в исследованиях генезиса, эволюции и современного этапа конституционализма. Советские конституции до 1977 г. не включали разделов либо статьи, которые бы заимствовали нормы международного права. Однако, в Конституции РСФСР 1978 г. в соответствии со ст. 32 утверждалось, что «общепризнанные международные нормы, относящиеся к правам человека, имеют преимущество перед законом РФ». Вступление в силу Конституции Российской Федерации 1993 г. привело к дискуссии между учеными, теоретиками и практиками, которые давали свое толкование положений конституции. С одной стороны, впервые в истории России был закреплен примат международного права. В конституционном документе говорится, что общепризнанные принципы и нормы международного права, и международные договоры Российской Федерации являются составной частью ее правовой системы. Если международным договором установлены иные правила, чем предусмотренные законом, то применяются правила международного договора (ч. 4 ст. 15). С другой стороны, согласно ч. 1 ст. 15 Конституции, она имеет высшую юридическую силу, прямое действие и применяется на всей территории Российской Федерации. Законы и иные правовые акты, принимаемые в Российской Федерации, не должны противоречить Конституции Российской Федерации. По мнению Г. И. Муромцева и Р. Т. Шамсон, содержание Конституции свидетельствует об интеграции России в общечеловеческую систему источников права, вершину которой составляют международные акты о правах человека, а основание - нормы права национального. Такой подход предполагает построение правового государства на национальном уровне, а также создание некоего его аналога на уровне международном. При этом предполагается признание:

1. Примата международного права перед правом национальным.

2. Примата естественных прав человека перед законодательством государства.

3. Правосубъектности индивида в сфере международного права и, как следствие, необходимости международно-правового механизма защиты индивида от произвола государства [12, с. 92].

Единой концепции конституционализма в современной правовой науке не существует. Однако, в связи с процессами демократизации, несомненный интерес вызывают различные подходы к анализу феномена демократии и связанных с ним процессов модернизации различных сфер конституционной, политико-правовой, социокультурной и других. Так американский ученый Чю Тили выделяет следующие подходы в изучении демократии: конституционный подход; сущностный подход; процедурный подход; модернизационный подход [13]. В отечественной правовой науке интерес к изучению институтов демократии, прежде всего в развитых цивилизованных странах, проявился широко. Сравнительно-правовые исследования затронули изучение основ конституционного строя; особенностей конституционного правосудия; социальных прав, их определения в различных современных конституциях; анализ права социального обе-

\section{Baikal Research Journal}

электронный научный журнал Байкальского государственного университета 
спечения и т. д. Внимание уделяется сравнительно-правовому анализу отдельных правовых институтов. Например, в трудах В. В. Чуксиной рассматриваются роль и формы участия правозащитных институтов на внутригосударственном и международном уровнях, особенности внесудебных правозащитных институтов, исследуется опыт России и зарубежных стран [14-16].

На практике утверждение приоритета международного права идет крайне медленно и противоречиво. Законодательство по-прежнему во многом не соответствует международным стандартам, а суды совершенно не готовы к применению норм международного права. В отечественной правовой науке, несмотря на примеры устоявшихся и успешно действующих «чужих" правовых институтов в других правовых системах, высказываются опасения о рецепции их и переносе на российскую правовую почву, что на наш взгляд вполне обоснованно. Так М. В. Немытина замечает, что не всегда понятно, почему при введении в нашей стране одного имеющего зарубежный аналог правового института берется за основу опыт США, другого - Франции, третьего - Германии. Не ясно, чем обусловлены предпочтения, оказанные той или иной стране в смысле заимствования ее правового опыта, влияют ли на этот выбор объективные обстоятельства. Заимствования чужого опыта правового развития, построения правовой системы и правового регулирования может оказаться не таким уж безобидным [17]

Элементы правового заимствования должны быть адаптированы к условиям государства. Подлежать рецепции могут юридическая техника, отдельные нормы права, правовые институты, юридическая практика, а также правовые идеи. Рецепция может иметь различные формы и варьировать в зависимости от глубины заимствования элементов национальных правовых систем других стран или мировой правовой системы. Глубокие заимствования могут привести к кардинальным изменениям правовой культуры конкретного государства. Данное обстоятельство определяет необходимость осторожного отношения к любым нововведениям, поскольку следует учитывать российское общественное мнение, которое изначально формируется в рамках существующей издавна правовой традиции. Например, полная реализация заимствованной правовой идеи - гарантии прав человека и гражданина, универсализации прав человека, воплощенной в положениях Конституции Российской Федерации 1993 г., зависела и зависит от уровня социально-экономического, политического развития государства, правового менталитета и др.

Общая политическая культура, исторические традиции и особенности религиозных воззрений оказывают существенное влияние на выбор гражданским обществом направления развития государства, правовых заимствований. Например, в 2008 г. Русская Православная Церковь (РПЦ) в рамках разработки своего подхода к развитию и реализации концепции прав человека утвердила документ «Основы учения Русской Православной Церкви о достоинстве, свободе и правах человека». В этом документе РПЦ излагает свой взгляд на развитие и реализацию концепции прав человека не только в России, но и в мире. С точки зрения РПЦ по мере секуляризации высокие принципы неотчуждаемых прав человека превратились в понятие о правах индивидуума вне его связи с Богом. Охрана свободы личности трансформировалась в охрану своеволия. Авторы документа считают, что сегодня христиане часто оказываются в условиях, когда государственные и общественные структуры принуждают их мыслить и поступать вопреки Божьим заповедям. Представители РПЦ говорят, что они не собираются навязывать свою концепцию прав человека светским властям, но хотят, чтобы к ней прислушались. В условиях, когда подавляющее большинство населения Российской Федерации позиционирует себя православными людьми, точка зре-

\section{Baikal Research Journal}

электронный научный журнал Байкальского государственного университета 
ния РПЦ может иметь огромное влияние на реализацию и адаптацию названной правовой идеи в государстве.

Таким образом, серьезным недостатком рецепции, переносов из зарубежного права заимствований, является отсутствие учета особенностей той социокультурной среды, в которой формировались правовые институты. Не отслеживаются особенности исторической эпохи, условий, в которых проходило формирование и развитие заимствованных институтов. Не выявляются экономические и социально-политические обстоятельства реализации этих правовых институтов в рамках конкретных правовых систем. Не смотря на то, что большинство исследователей признают закономерный характер сближения современных национальных правовых систем, обусловленный объективными потребностями в целом человеческого общества. Необоснованное копирование той или иной правовой модели, того или иного правового института, которые эффективны в каком-либо государстве, может не дать ожидаемого результата. Перенимая мировой опыт, теоретикам и практикам следует учитывать, что право будет действовать эффективно только тогда, когда созданы условия для адаптации нововведенных правовых институтов с учетом исторически сложившихся в государстве правовых традиций, юридической доктрины, самобытности правовой культуры и т. д. А. В. Муранова обратила внимание, что 3. М. Черниловский первый поставил проблему правовой традиции как фактора, ограничивающего реформы права. Она отмечает, что глубинные правовые традиции проникают медленно, ...может быть отмечено сильное консервативное воздействие старой морали и религии. Правовые традиции могут способствовать или, напротив, препятствовать развитию права [18, с. 120].

В вопросах определения пути дальнейшего развития российского государства в правовой науке, относительно правовых заимствований, можно выделить два подхода:

1. Максимальное использование правовых институтов, характерных для современного цивилизованного мира и действующего международного права.

2. Сохранение приоритета правовых институтов в соответствии с национальными правовыми традициями.

Представляется, что именно компаративистика, сравнительно-правовые исследования могут сгладить противоречия между этими подходами. На основе выработки критериев изучения зарубежного опыта, наука должна способствовать не слепому заимствованию имеющегося позитивного зарубежного опыта, а модернизации национальной правовой системы с учетом этого опыта на основе и при сохранении правовых традиций.

В 2010 г. исполнилось 85 лет со дня основания Института законодательства и сравнительного правоведения при Правительстве Российской Федерации. Стремительные изменения в экономической и социальной сферах, появление новых государственных институтов, динамичное развитие законодательства способствуют определению новых направлений научной деятельности, обновлению концепции законодательства. В институте сегодня действуют три научно-исследовательских центра, соответствующие направлениям научной деятельности:

1. Публично-правовые исследования.

2. Частноправовые исследования.

3. Сравнительно-правовые исследования.

В дни юбилейных торжеств, отмечая важность работы данного института, было обращено внимание на то, что «актуальной научной задачей остается исследование процессов расширяющегося соотношения принципов, институтов и норм национального законодательства и международного права. Большое внима-

\section{Baikal Research Journal}

электронный научный журнал Байкальского государственного университета 
ние уделяется как анализу влияния международного права на законодательство разных стран, так и обратному влиянию. Данный подход позволяет увеличить спектр правового анализа и более отчетливо показать роль российской правовой системы в правовом развитии современного мира» [19, с. 9]. В конечном итоге только тот, кто владеет знаниями, может правильно определить стратегию развития государства.

\section{Список использованной литературы}

1. Леже Р. Великие правовые системы современности: сравнительно-правовой подход : пер. с фр. / Р. Леже. - М. : Волтерс Клувер, 2010. - 523 с.

2. Марченко М. Н. Сравнительное правоведение / М. Н. Марченко. - М. : Проспект, 2011. - $781 \mathrm{c.}$

3. Чиркин В. Е. Сравнительное правоведение : учеб. для магистратуры / В. Е. Чиркин. - М. : Междунар. отношения, 2012. - 336 с.

4. Грушин Б. А. Очерки логики исторического исследования / Б. А. Грушин. - М. : Высш. шк., 1961. - 214 с.

5. Ковалевский М. М. Историко-сравнительный метод в юриспруденции и приемы изучения истории права / М. М. Ковалевский // Антология украинской компаративистики XIX-XX столетий / под ред. О. В. Кресиной. - Киев : Логос, 2008. - Вып. 5. C. $112-127$.

6. Цвайгерт К. Введение в сравнительное правоведение в сфере частного права : в 2 т. : пер. с нем. / К. Цвайгерт, Х. Кетц. - М. : Междунар. отношения, 2000. — Т. 1: Основы. $-480 \mathrm{c}$.

7. Осакве К. Сравнительное правоведение: схематический комментарий : учеб.-практ. пособие / К. Осакве. - М. : Юрист, 2008. - 759 с.

8. Нерсесянц В. С. Юриспруденция. Введение в курс общей теории права и государства / В. С. Нерсесянц. - М. : Норма : Норма-Инфра-М, 2002. - 282 с.

9. Правовая политика : словарь и проект концепции / под ред. А. В. Малько. - Саратов : Изд-во Сарат. гос. акад. права, 2010. - 287 с.

10. Муромцев Г. И. О некоторых методологических проблемах современной российской юридической науки / Г. И. Муромцев // Вестник Российского университета дружбы народов. -2007 . - № 1. - С. 5-15.

11. Тихомиров Ю. А. Международный конгресс компаративистов / Ю. А. Тихомиров // Журнал российского права. - 2006. - № 10. - С. 149-151.

12. Муромцев Г. И. Соотношение международного и внутригосударственного права (эволюция основных подходов) / Г. И. Муромцев, Рияд Таха Шамсон // Вестник Российского университета дружбы народов. Сер.: Юридические науки. - 2002. - № 2. - С. 85-93.

13. Тилли Ч. Демократия : пер. с англ. / Ч. Тилли. - М. : Изд-во Ин-та обществ. проектирования, 2007. - 264 с.

14. Чуксина В. В. Национальные правозащитные институты в контексте взаимодействия внутригосударственных и международных механизмов защиты прав человека / В. В. Чуксина // Известия Иркутской государственной экономической академии. 2011. - № 4. - C. 158-162.

15. Чуксина В. В. Институт омбудсмена как национальный превентивный механизм против пыток / В. В. Чуксина // Известия Иркутской государственной экономической академии. - 2012. - № 3. - С. 140-144.

16. Чуксина В. В. Внесудебные специализированные правозащитные институты: опыт России и зарубежных стран / В. В. Чуксина // Арбитражный и гражданский процесс. 2009. - № 2. - С. 5-9.

17. Немытина М. В. Пространство сравнительно-правовых исследований / М. В. Немытина // Методология сравнительно-правовых исследований. ЗЖидковские чтения : материалы Всерос. науч. конф. Москва, 30 марта 2012 г. / под ред. Г. И. Муромцева, М. В. Немытиной. - М. : Рос. ун-т дружбы народов, 2013. - 444 с.

18. Мурунова А. В. Правовые традиции России и Запада: сравнительно-правовой анализ. / А. В. Мурунова // Контуры глобальных трансформаций: политика, экономика, право. - 2011. - Вып. 5, т. 4. - С. 120-126.

\section{Baikal Research Journal}


19. Хабриева Т. Я. Творческий потенциал науки / Т. Я. Хабриева, Ю. А. Тихомиров // Журнал российского права. - 2010. - № 10. - С. 5-11.

\section{References}

1. Legeais Raymond. Les grands sistemes de droit contemporains: une approche comparative. Paris, LexisNexic Litec, 2004. 457 p. (Russ. ed.: Legeais Raymond. Velikie pravovye sistemy sovremennosti: sravnitel'no-pravovoi podkhod. Great Legal Systems of Modern Times: Comparative and legal Approaches of Moscow, Volters Kluver Publ., 2010. 523 p.

2. Marchenko M. N. Sravnitel'noe pravovedenie [Comparative Legal Science]. Moscow, Prospekt Publ., 2011. 781 p.

3. Chirkin V. E. Sravnitel'noe pravovedenie [Comparative Legal Science]. Moscow, Mezhdunarodnye otnosheniya Publ., 2012. 336 p.

4. Grushin B. A. Ocherki logiki istoricheskogo issledovaniya [Sketches of historical investigation logics]. Moscow, Vysshaya shkola Publ., 1961. 214 p.

5. Kovalevsky M. M. Historical and comparative method in jurisprudence and tools of studying history of law. In Kresina O. V. (ed.). Antologiya ukrainskoi komparativistiki XIX$X X$ stoletii [Anthology of Ukrainian Comparativistics of XIX-XX centuries]. Kiev, Logos Publ., 2008, iss. 5, pp. 112-127. (In Russian).

6. Zweigert K., Kotz H. Einfuhrung in die Rechtsvergleichung auf dem Gebiete des Privatrechts. Tubingen, 1984. (Russ. ed.: Zweigert K., Kotz H. Vvedenie v sravnitel'noe pravovedenie $v$ sfere chastnogo prava. Moscow, Mezhdunarodnye otnosheniya Publ., 2000. Vol. 1. 480 p.).

7. Osakwe Christopher. Sravnitel'noe pravovedenie: skhematicheskii kommentarii [Comparative Legal Science: Schematic Commentary]. Moscow, Yurist Publ., 2008. 759 p.

8. Nersesyants V. S. Yurisprudentsiya. Vvedenie $v$ kurs obshchei teorii prava $i$ gosudarstva [Jurisprudence. Introduction into the Course of General Theory of Law and State]. Moscow, Norma Publ., Norma-Infra-M Publ., 2002. 282 p.

9. Mal'ko A. V. (ed.). Pravovaya politika: slovar' i proekt kontseptsii [Legal policy: dictionary and project of the concept]. Saratov State Law Academy Publ., 2010. 287 p.

10. Muromtsev G. I. On some methodological problems of modern Russian juridical science. Vestnik Rossiiskogo universiteta druzhby narodov = Bulletin of People's Friendship University of Russia, 2007, no. 1, pp. 5-15. (In Russian).

11. Tikhomirov Yu. A. International Congress of Comparatists. Zhurnal rossiyskogo pra $v a=$ Journal of Russian Law, 2006, no. 10, pp. 149-151. (In Russian).

12. Muromtsev G. I., Riyad Takha Shamson. Correlation of international and national laws (evolution of main approaches). Vestnik Rossiiskogo universiteta druzhby narodov. Seriya Yuridicheskie nauki = Bulletin of People's Friendship University of Russia, Series: Juridical Sciences, 2002, no. 2, pp. 85-93. (In Russian).

13. Tilli Charles. Democracy. Cambridge University Press, 2007. 246 p. (Russ. ed.: Tilli Charles. Demokratiya. Moscow, Institute of Public Design Publ., 2007. 264 p.).

14. Chuksina V. V. National human rights institutions in the context of interaction of domestic and international mechanisms of human rights protection. Izvestiya Irkutskoi gosudarstvennoi ekonomicheskoi akademii = Bulletin of Irkutsk State Economics Academy, 2011, no. 4, pp. 158-162. (In Russian).

15. Chuksina V. V. Institution of ombudsman as a national preventive mechanism against torture. Izvestiya Irkutskoi gosudarstvennoi ekonomicheskoi akademii = Bulletin of Irkutsk State Economics Academy, 2012, no. 3, pp. 140-144. (In Russian).

16. Chuksina V. V. Extrajudicial specialized human rights institutions: experience of Russia and other countries. Arbitrazhnyi $i$ grazhdanskii protsess = Arbitration and Civil Proceedings, 2009, no. 2, pp. 5-9. (In Russian).

17. Nemytina M. V. Space of comparative and legal investigations. In Muromtsev G. I., Nemytina M. V. (eds). Metodologiya sravnitel'no-pravovykh issledovanii. Zhidkovskie chteniya. Materialy Vserossiiskoi nauchnoi konferentsii. Moskva, 30 marta 2012 g. [Methodology of Comparative Legal Studies. Zhidkov Readings. All-Russian Scientific Conference. Moscow, March 30, 2012]. Moscow, People's Friendship University of Russia Publ., 2013. 444 p. (In Russian).

\section{Baikal Research Journal}


18. Murunova A. V. Legal Traditions of Russia and the West: Comparative Legal Analysis. Kontury global'nykh transformatsii: politika, ekonomika, pravo = Contours of global transformations: politics, economics, law, 2011, iss. 5, vol. 4, pp. 120-126. (In Russian).

19. Khabriyeva T. Ya., Tikhomirov Yu. A. Creative potential of science. Zhurnal rossiyskogo prava = Journal of Russian Law, 2010, no. 10, pp. 5-11. (In Russian).

\section{Информация об авторе}

Левченко Ирина Владимировна - доцент, кафедра теории государства и права и социально-правовых дисциплин, Байкальский государственный университет, 664003, г. Иркутск, ул. Ленина, 11, e-mail: irina-levchenko@bk.ru.

\section{Author}

Irina V. Levchenko - Associate Professor, Chair of Theory of State and Law and SocioLegal Disciplines, Baikal State University, 11 Lenin St., 664003, Irkutsk, Russian Federation; e-mail: irina-levchenko@bk.ru.

\section{Библиографическое описание статьи}

Левченко И. В. Роль сравнительно-правовых исследований в определении вектора развития государства / И. В. Левченко // Baikal Research Journal. — 2017. — Т. 8, № 1. DOI: $10.17150 / 2411-6262.2017 .8(1) .25$.

\section{Reference to article}

Levchenko I. V. Role of comparative legal studies in determining vector of state development. Baikal Research Journal, 2017, vol. 8, no. 1. DOI: 10.17150/2411-6262.2017.8(1).25. (In Russian).

\section{Baikal Research Journal}

